\title{
Technical Analysis on Markets with Memory
}

\author{
PhD Flifel Kaouther \\ Contractual teacher in finance, money and banks \\ Institut des Hautes Etudes Commerciales \\ IHEC Carthage Présidence-2016 Tunis \\ Tel : 216-2280-2093 E-mail: flifelkaouther@yahoo.fr
}

Received: March 23, 2013 Accepted: April 5, 2013

doi:10.5296/ber.v3i1.3420

URL: http://dx.doi.org/10.5296/ber.v3i1.3420

\begin{abstract}
Economists note that financial markets are experiencing alternating periods of euphoria and depression. The question they ask is to know how to "beat the market". Some, relying on the analysis of covariance, affirm portfolio diversification, others lean towards the reflexive interaction "players" and the market, others base their theory on their own experiences, give particular attention to the intrinsic value of the business and provide a strong distinction between the investor and the speculator. In this article we will discuss the relative merits of two classic strategies of prediction, "fundamental analysis" versus "technical analysis "(or" Chartism ") and this for different cases of figs for markets with and without memory.
\end{abstract}

Keywords : Technical analysis, Fundamental analysis, Technical indicator, Long memory.

\section{Introduction}

For the trader the institutional investor is looking to buy at the lowest and sell at the highest to maximize the gain. The art of the investor is to choose the best investment. This important observation highlights the notion of risk. The act of selection is not reduced only to maximize capital gains, but also to manage risk involved.

Two angles of analysis emerge: Fundamental analysis based on the quality of the investment and the society to which is attached the support, and technical analysis, based on the other criteria, addresses the problem quantitatively, and uses mathematics as an analytical tool. Thus we can say that these two approaches are not at all opposed, they interact. We cannot disregard one or the other approaches. But although it is more convenient to treat them separately, it should be regarded as complementary. 
But before talking about predicting we must ask the questions: we talk about what type of market is it?

More recently, the Hurst exponent (Hurst, 1951) emerged in economic research as a measure of ranking of a time series based on their long-term dependencies (Peters, 1991; Peters, 1994) that may be beneficial to identify which markets are more predictable. In addition, research has concluded on the link between the level of economic development of countries and the detection of long memory (long memory is synonymous with weak markets and vice versa: Imed Limam (2003)).

The purpose of this study is to determine, by a posteriori analysis of the market share from 21 indices, (1) whether the strategy of the speculator who works in the following indicators of technical analysis is better than the investor who adopts a passive index management consisting on the concept of "buy and hold" (2) how can we confirm what technical analysts argue, saying that some indicators work better in some contexts of stock markets (up or down, memory or efficient, developed or considered as an emerging power).

After a review of the literature we will first try to revisit the concepts of efficiency, long memory, and the basics of technical and fundamental analysis to understanding the concepts of indicator before describing the conditions of simulation. Then we will present data quickly and the method of the research, to finally conclude with the results.

To fully explore this issue we have had the opportunity to live, for each stock index high contrasting situations: sometimes a period of euphoria and sometimes a phase of depression. We will therefore repeat our simulations on the 21 indices to know whether there were efficient and reliable indicators best suited to a bullish or bearish.

\section{Literature Review}

Several debates have been a manifestation of a controversy over the relative merits of different financial strategies. This is not purely scientific or purely technical or purely economic, it mixes different levels and actors in these different worlds. Economists have invested this controversy with multiple objectives since the 1930s [Cowles, 1933] : This was as much to show the vanity of advice of financial intermediaries, these "applied economists", than trying to establish statements to the attention of the scientific community on the benefits (or not) of markets.

This strategy of disclosure did not prevent economists to keep an interested eye on the opportunity of the financial profitability of their discoveries (MacKenzie and Millo (2003)). The same ambiguity is found on the side of market professionals. If they oppose at first sight to exploit first of all the chances of winning, they do not neglect the theoretical controversy to show the superiority of methods to which they are attached. The markets are not only populated by "sellers", indifferent and opportunistic operators ready to promote any method as long as it generates financial opportunities that are favorable to them, but also "true believers" who think they have found the key to understanding the market, key that they experience intellectually by winning and making earn money. It is within these different "true believers" that emerge the most hostly debates. Their typology ("fundamentalists," "contrarian," "chartists") is not closed. 


\section{MInstitute ${ }^{\text {Mank }}$}

Business and Economic Research ISSN 2162-4860 2013, Vol. 3, No. 1

But still these two poles are found in the debate: the fundamental economic analysis and chartist analysis.

Since its inception, the research on technical analysis was generally inconsistent. The first studies were conducted by Alexander (1961 and 1964), and Fama-Blume (1966) who suggested that the excess returns could not be achieved by taking investment decisions based on filtering rules. However, Sweeney (1988) later reviewed the data used by Fama and Blume (1966) and found that the filter rules applied to fifteen of the thirty securities in the Dow Jones earned a higher excess return to that of the purchase conservation. The excess returns exist since a number of years following the end of the sample of Fama and Blume. The number of studies on the technical indicators have increased in the 1990s, as well as methods used to test the trading rules. However, the existing body of research has been unable to conclude on its profitability.

Oberlechner Thomas (2001) presents the results of a questionnaire and an interview survey on the perceived importance of technical and fundamental analysis between traders and financial journalists in Frankfurt, London, Vienna and Zurich. Traders confirm that, on the two methods of forecasting, technical analysis is more important than the other.

Sanjay Gupta and Sehgal Meenkashi (2005) presents the survey which aims to provide ideas on how technical traders operate in the financial market and the trading strategies that they adopt. The survey covered the technical operators with a long and active business case for the Indian market. In this study also, it is observed that the respondents in the sample tend to use technical analysis for stock selection.

Camillo Lento (2009) studied the link between nine trading rules and the Hurst exponent $(\mathrm{H})$ on fifteen of the largest global equity markets in order to determine if technical trading rules are more profitable in markets characterized by long-term dependencies. He find that there is some association between the profitability of trading rules and the Hurst exponent. However, the fact that many of the trading rules were profitable in markets with low $\mathrm{H}$ suggests that the trading rules are able to generate useful information by processing past prices into a more informative trading signal than that provided by the random-walk model.

Jenni.L Bettman Stephen.J.Sault, Emma.J Schultz (2009), proposes an equity valuation model integrating fundamental and technical analysis, they tend to recognize their potential as a complement rather than substitutes. The tests confirm the complementary nature between the two analyses.

Any existing literature provides inconclusive evidence on the profitability of technical indicators. In addition, the literature on the fractal nature of financial markets does not investigate whether the identified dependencies can be used to obtain excess returns from the rules of technical analysis. The combination of the literature of these two schools may provide grounds for developing new knowledge about the profitability of technical indicators.

This reasoning is the basis of the following research question:

Is there an association between returns of technical analysis and long term dependencies, as 
identified by the $\mathrm{H}$ ?

\section{Simulation}

The simulation is intended as an objective: First of all to seek the best technical indicators and secondly to know which of systems of trading can beat a passive index management. We must first distinguish between fixed data describing the trading system, of variables that will change with each scenario. The composition of the portfolio at the beginning of simulation and the technical indicators tested are the two elements that do not change from one scenario to another:

1. Sample of indices: The choice of sample analysis has focused on the values forming the indices of 21 countries grouped according to their levels of development.

2. Technical Indicators: These indicators are those delivered with the Metastock. They are 8 in number.

The graphical analysis of these indices suggests that it is interesting to divide these periods into distinct phases to assess the technical analysis in different market configurations. Will be conducted from this software 83 simulations (see appendix 1).

The evaluation of the performance of automated trading systems will be done by considering three criteria:

1. Profitability: Capital gains (expressed in percentage of the amount invested at the beginning of period)

2. Reliability: The ratio between winning trades and losing trades (a ratio of 0.5 means that there is one success for two failures)

3. Quality: The gain / loss ratio (a ratio of 3 means there are 3 units earned cash for one lost).

We will conduct a classification of indicators according to the criteria of profitability (net gain), because it is one that is closer to the concerns of the investor. The others will be used to compare the behavior of different technical indicators.

The measured profitability is an average of gains. This means that an underperforming indicator can also provide good results for a particular title. Trading systems will only be selected and considered interesting if their performance exceeds that of the indices used for reference as representative of the market.

\section{Results}

\subsection{Comparison between Technical Indicators and Passive Management:}

In each simulation, the computer chooses - according to the result provided by the indicator and decision rules - between buy, sell or hold securities within the rules of negotiation defined. The positions are closed at or before the last day of the period. The computer repeats this for all indices selected. Then he moves to another indicator and takes up the simulation.

Thus on the study period, the computer makes decisions (number of trading days $\mathrm{x}$ number of 
indicators for each index (here we will use the eight most cited indicators in finance)). Performance shown is an average gain, which means that some couples (indicator; title) offer better performance than the others. According to the analyzes and results (see appendix 2) we removed the following aspects:

- The technical indicators are supposed to reduce the risk of decision. But strangely the decisions taken by the automatic trading software lead to more failures (making a loss) than successes. This means that over the period, indicators get more bad decisions than good.

- Overall the technical indicators are not an aid to effective decision making, quite the contrary they lead to make more bad decisions than good. In addition we cannot conclude that there is an indicator more efficient than the others, it is likely that decisions would probably be improved by combining relevant indicators, but all computers in the world would fail to simulate all possible combinations.

- We notice that in the long term, a system deciding randomly should do better by obtaining a ratio Success/Failure greater or equal to one. Therefore, it is not possible to trust on the technical indicators to improve the probability of making a good investment decision. They are therefore not reliable.

- But, despite that they are of good quality. The unreliability of the indicators is offset by good quality, in other words a relative gain / loss rate which is high. Indicators provide gains 1.87 times higher than losses. This means that the right decisions make earning more money than the bad do by losing.

- In phase of euphoria technical analysis do worst than the market ... Simulations of automated trading system shows once again that the performance of the technical indicators is significantly worse than passive index management (sometimes even negative for some indices). In addition, these indicators are not reliable since there are more chances of making a bad decision that good one. This disadvantage is compensated by the good quality (gain / loss ratio) of indicator, and this reinforces the conclusion that it is better to go with a wave bullish.

- In phase of depression technical analysis is better than the market ... And in this difficult stock market, curiously, the majority of automated trading systems, without exception, offer better results than the strategy of buying the market and later resell. Because it allows ... stay away.

Why? The first thing that crosses your mind is that the automated trading system, more rational than investor, reacts intelligently by analyzing the laws of supply and demand and makes decisions devoid of all emotion. By combining "intelligence" and rationality, the simulator takes advantage of the inconsistency of the market. But then if the automated trading system is more sensible in phase of depression why is he not in phase of euphoria?

Ultimately Technical analysis is it a defensive tool? Therefore, no definitive conclusion, we think that technical analysis works best in defensive mode (leave the market and stay away when it says) rather than offensive mode (enter and exit when she says ). So technical analysis may be a method to listen when we want to sale and use with caution in the case of purchasing.

In response to the question of whether there are indicators to outperform the market, the answer 
is no. Various simulations show that in the context of the study, technical analysis is of no interest. In fact :

1- It is not reliable: Technical indicators are not a great help to the decision because they do not increase the success rate: the failure rate even exceeds the success rate.

2- It is a waste of time: The analysis technique requires attention and daily availability to identify the signals and pass orders immediately. Various simulations indicate that it is better to invest and wait rather than spending hours analyzing the course. Only exception to this rule, the case of a sustained bear market environment, a situation where it is better to go out and reallocate assets,

3- There is no ideal technical indicator: It is impossible to know what indicator will perform in the future.

The only advantage that we can recognize to technical analysis, it is the advantage of putting the index away from the fall in the period 2000-2010 and inviting it to not return to the market or leave quickly. To the question of knowing if it is better to follow a passive index management to the active one guided by technical analysis, computer, after analyzing almost millions of situations, responds that it is better to choose to buy the market and then wait, to speculate on the future price movements. If the adepts of technical analysis persist in their error it may be because they do not lose, fortunately, every time. Reassure them that technical analysis is not ready to fall into disuse for several reasons:

- First, it gives clear and argued answers. This gives it a double advantage on the fundamental analysis: to know how to explain the evolution of courses, provide forecasts and even advice,

- Then it has the support of the media and financial intermediaries not only for the reason mentioned above, but also because it allows them to develop their turnover,

- It won the public interest for its apparent credibility. To cite just one example of investors' preference for technical analysis, a French newspaper, specializing in this market, publishes an average of 3 books on technical analysis for a single work of fundamental analysis. The reasons may also be sought in the graphical and mathematical complexity of technical analysis which is a guarantee of seriousness.

- Finally, even if we have not mentioned, it gives good results in the short term. Traders cannot ignore it. And if it works better in the short term, it is because the price of a security or a currency that rises at a given time has a high chance to continue to rise a few minutes later to form an ascending way. It is almost as if motionless at the edge of a road, you see traffic. It's a little as if, stationary beside a road, you see traffic. There is little chance that a car suddenly makes turn around or mak abruptly reverse. In other words, technical analysis provides indications more reliable in the short-term than the long-term. Its usefulness in this situation could also give rise to another line of research.

\subsection{Long Memory Versus Technical Analysis:}

This section attempts to answer the following question: Is there an association between the 
profitability of technical analysis and detection of long memory, as identified by the $\mathrm{H}$ (excess returns exist when $\mathrm{H}>0.5)$ ? The different results are summarized in the tables in appendix 3.

- The technical indicators were profitable in emerging markets and some markets in some emerging powers. The strategies MACD and Relative Strength Index are the least profitable. Rules Bollinger Bands, TRIX and Zig Zag were profitable in most markets.

- In addition, we note from the following tables, that the results provide evidence that the benefits of technical analysis are partially explained by the long memory in time series. The tables show that the benefits are lowest for the index with the lowest value of $\mathrm{H}$ and increase in association with an increase in $\mathrm{H}$.

\section{Conclusion}

The analytical and scientific character of technical analysis, its apparent complexity and its ability to always provide clear answers to questions asked by the investor gives it a credibility that can exploit the media and financial intermediaries.

This credibility is harmed by the objective study of the performance of the technical indicators over the period studied, but also in bullish or bearish contexts.

To remove all subjectivity in the study, it is a computer program that simulates these results lead us to the following general conclusions:

(1) Over a period of 10 years, a certain number of technical indicators allow to obtain a return in excess of a "buy and hold" strategy. These indicators owe their success to the many inputs and outputs in market. However, they are not reliable (there is as much chance of making a bad decision that good), but offset this disadvantage by good quality (the gains are higher). then

(2) Technical indicators perform better than passive management in times of depression, because they allow investors to stay away from the market. This suggests that technical analysis has more defensive role than offensive. However, there is no technical indicator "miracle" as much for its decision reliability (in general, the indicators are wrong half the time) for his consistent performance in both the rising or falling contexts. and finally

(3) The study suggest That the kind of a fractal time series explains a significant portion of the profits generated by technical analysis. The researchers should continue to investigate how the $\mathrm{H}$ in one sub period can be used, ex ante, to identify which time series will yield the most fruitful results from technical analysis. This paper has made a contribution in this area by suggesting that the sub-periods with daily data are able to predict future sub-period profits from technical trading rules. Researchers are encouraged to continue research in this area to provide a significant impact to traders and investors.

\section{References}

A Cowles. (1993) Can stock market forecasters forecast?, Econometrica: Journal of the Econometric Society, 1933-JSTOR.

Alexander, S. (1961). Price Movements in Speculative Markets: Trends or Random Walks. 
Industrial Management Review, 2, 7-26.

Alexander, S. (1964). Price Movements in Speculative Markets: Trends or Random Walks, No. 2 in P. Cootnered (ed.), The Random Character of Stock Market Prices, MIT Press, Cambridge, MA.

Bender, C., Sottinen, T., and Valkeila, E. (2006). Arbitrage with fractional Brownian motion. Theory of Stochastic Processes, 12(28), 3-4.

Camillo Lento, (2009),. Long-Term Dependencies and the Profitability of Technical Analysis., International Research. Journal of Finance and Economics, 29, 126-133.

Fama, E., \& Blume, M. (1966). Filter Tests and Stock Market Trading. Journal of Business, 39, 226-241. http://dx.doi.org/10.1086/294849

Hurst, H. (1951). Long-term storage of reservoirs: an experimental study., Transactions of the American Society of Civil Engineers 116, 770-799.

Imed Limam. (2003). Is Long Memory a Property of Thin Stock Markets? International Evidence Using Arab Countries. Review of Middle East Economics and Finance - Rev Middle East Econ Finance, vol. 1, no. 3. http://dx.doi.org/10.1080/1475368032000158241

Jenni. L. Bettman, Stephen. J. Salut, \& Emmenn L Schultz, (2009). Fundamental and Technical Analysis, Substitutes of Compliments., Accounting and Finance 49(2009), 21-36. http://dx.doi.org/10.1111/j.1467-629X.2008.00277.x

MacKenzie, D., \& Y. Millo. (2003). Constructing a Market, Performing Theory : The Historical Sociology of a Financial Derivatives Exchange., American Journal of Sociology, 109, 107-145. http://dx.doi.org/10.1086/374404

Peters, E., (1991). Chaos and Order in the Capital Markets: A new view of cycles, prices, and market volatility.. New York: Wiley. International Research Journal of Finance and Economics, Issue 29133.

Peters, E., (1994). Fractal Market Analysis: applying chaos theory to investment and economics. New York: Wiley.

Sanjay Sehgal \& Meenkashi Gupta, (2005). Technical analysis in the Indian Capital Market. A Survery, Decision, 32(1), 91-116.

Sweeney, R. J. (1988). Some New Filter Rule Tests: Methods and Results. Journal of Financial Quantitative Analysis, 23, 87-92. http://dx.doi.org/10.2307/2331068

Thomas Oberlechner. (2001). Importance of technical and fundamental analysis in the European foreign exchange market. International Journal of Finance \& Economics, 2001-Wiley Online Library.

\section{Appendix}

Appendix 1. Trend and Growth Rate of Each Index for Each Period 


\section{Macrothink}

Business and Economic Research

ISSN 2162-4860

2013, Vol. 3, No. 1

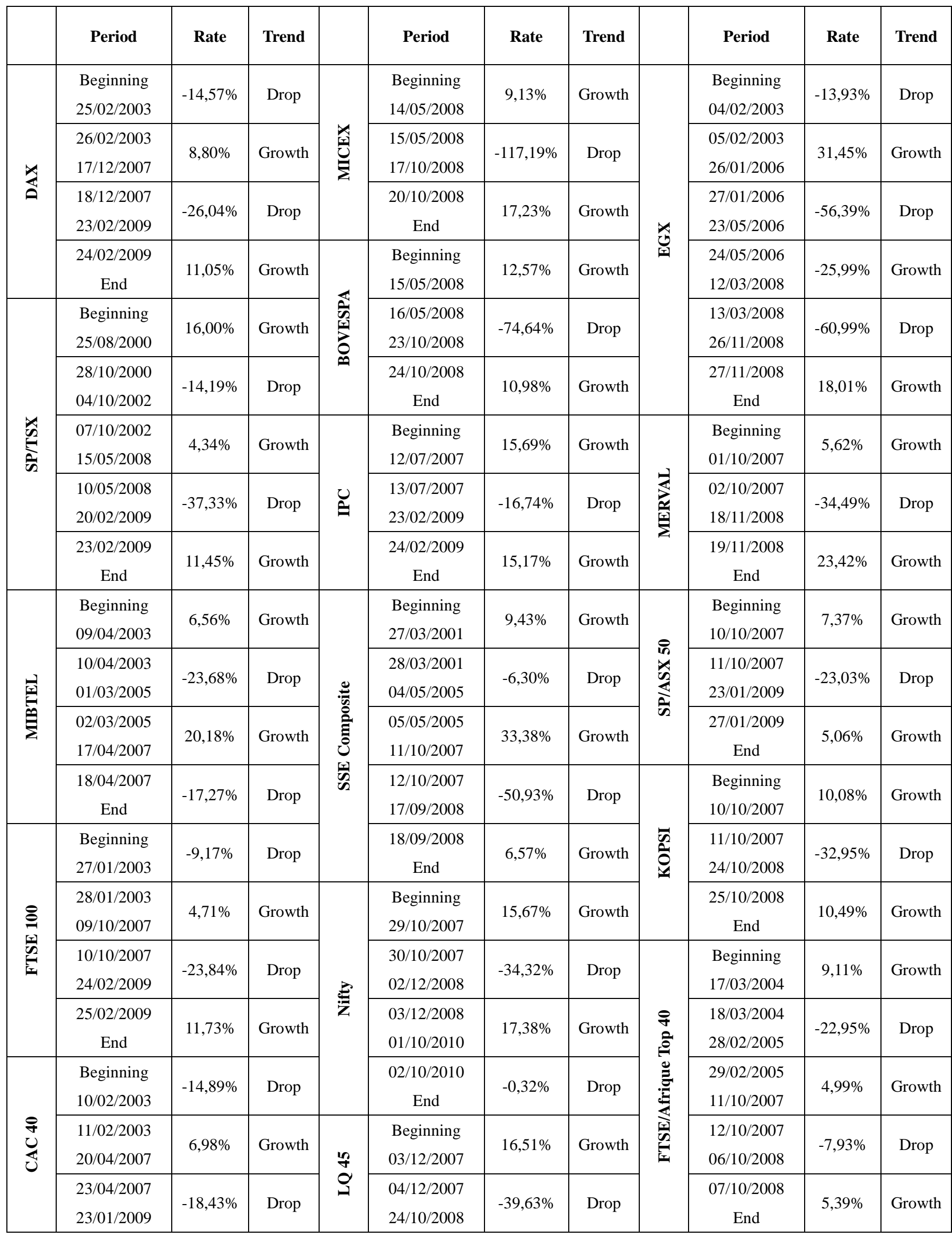




\section{NI Macrothink}

Business and Economic Research

ISSN 2162-4860

2013, Vol. 3, No. 1

\begin{tabular}{|c|c|c|c|c|c|c|c|c|c|c|c|}
\hline & $\begin{array}{c}\text { 26/01/2009 } \\
\text { End }\end{array}$ & $5,98 \%$ & Growth & & $\begin{array}{c}27 / 10 / 2008 \\
\text { End }\end{array}$ & $20,33 \%$ & Growth & \multirow{6}{*}{ 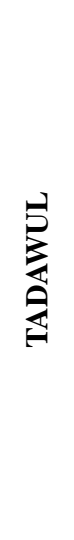 } & $\begin{array}{l}\text { Beginning } \\
20 / 02 / 2006\end{array}$ & $28,06 \%$ & Growth \\
\hline \multirow{5}{*}{ 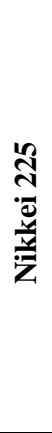 } & $\begin{array}{c}\text { Beginning } \\
\text { 20/02/2003 }\end{array}$ & $-9,51 \%$ & Drop & \multirow{7}{*}{ 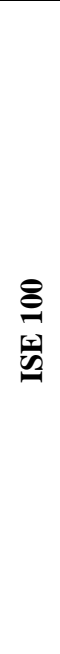 } & $\begin{array}{l}\text { Beginning } \\
13 / 08 / 2001\end{array}$ & $-46,54 \%$ & Drop & & $\begin{array}{l}21 / 02 / 2006 \\
16 / 04 / 2007\end{array}$ & $-34,53 \%$ & Drop \\
\hline & $26 / 02 / 2003$ & $8,57 \%$ & Growth & & 14/08/2001 & $14,61 \%$ & Growth & & 17/04/2007 & $24,38 \%$ & Growth \\
\hline & $01 / 06 / 2007$ & \multirow[b]{2}{*}{$-23,97 \%$} & \multirow[b]{2}{*}{ Drop } & & $25 / 01 / 2006$ & & & & $18 / 12 / 2007$ & & \\
\hline & $23 / 01 / 2009$ & & & & $12 / 06 / 2006$ & $-47,93 \%$ & Drop & & 06/10/2008 & $-26,45 \%$ & Drop \\
\hline & $\begin{array}{c}\text { 26/01/2009 } \\
\text { End }\end{array}$ & $4,93 \%$ & Growth & & $\begin{array}{l}13 / 06 / 2006 \\
25 / 09 / 2007\end{array}$ & $31,76 \%$ & Growth & & $\begin{array}{c}\text { 07/10/2008 } \\
\text { End }\end{array}$ & $6,92 \%$ & Growth \\
\hline \multirow{5}{*}{$\begin{array}{l}\text { के } \\
\text { के }\end{array}$} & $\begin{array}{c}\text { Beginning } \\
27 / 01 / 2003\end{array}$ & $-9,17 \%$ & Drop & & $\begin{array}{l}26 / 09 / 2007 \\
16 / 09 / 2008\end{array}$ & $-38,30 \%$ & Drop & \multirow{2}{*}{ 肴 } & $\begin{array}{l}\text { Beginning } \\
18 / 02 / 2003\end{array}$ & $-5,17 \%$ & Drop \\
\hline & $\begin{array}{l}28 / 01 / 2003 \\
01 / 10 / 2007\end{array}$ & $4,71 \%$ & Growth & & $\begin{array}{c}17 / 09 / 2008 \\
\text { End }\end{array}$ & $18,66 \%$ & Growth & & $\begin{array}{c}19 / 02 / 2003 \\
\text { End }\end{array}$ & $11,24 \%$ & Growth \\
\hline & $02 / 10 / 2007$ & $2284 \%$ & Drot & & & & & & & & \\
\hline & $27 / 02 / 2009$ & $-25,0+70$ & Diop & & & & & & & & \\
\hline & $\begin{array}{c}02 / 03 / 2009 \\
\text { End }\end{array}$ & $11,73 \%$ & Growth & & & & & & & & \\
\hline
\end{tabular}

Appendix 2. Simulation Returns Indices of the Sample Countries

\begin{tabular}{|c|c|c|c|c|c|c|c|c|c|c|c|c|c|c|c|c|c|}
\hline & \multicolumn{4}{|c|}{ Germany } & \multicolumn{5}{|c|}{ Canada } & \multicolumn{4}{|c|}{ Italy } & \multicolumn{4}{|c|}{ USA } \\
\hline & 1 & 2 & 3 & 4 & 1 & 2 & 3 & 4 & 5 & 1 & 2 & 3 & 4 & 1 & 2 & 3 & 4 \\
\hline $\mathrm{T} \%$ & $-14,6$ & 8,8 & $-26,0$ & 11,1 & 16,0 & $-14,2$ & 4,3 & $-37,3$ & 11,5 & 6,6 & $-23,7$ & 20,2 & $-17,3$ & $-9,2$ & 4,7 & $-23,8$ & 11,7 \\
\hline $\mathrm{G} \%$ & 5,0 & 2,8 & 5,2 & $-1,4$ & 7,5 & 7,3 & 9,6 & 5,6 & $-4,8$ & 12,3 & 12,2 & 3,1 & 9,6 & $-14,6$ & 5,7 & 12,6 & $-6,3$ \\
\hline NT & 475,5 & 478,3 & 273,4 & 458,6 & 148,3 & 479,1 & 479,1 & 170,1 & 443,1 & 479,1 & 450,1 & 463,1 & 479,1 & 479,1 & 479,1 & 334,1 & 443,1 \\
\hline $\mathrm{F}$ & 444,5 & 477,6 & 256,1 & 400,4 & 138,4 & 479,1 & 449,5 & 160,0 & 417,9 & 448,1 & 422,8 & 433,6 & 450,4 & 448,9 & 450,3 & 315,4 & 416,3 \\
\hline$S$ & 142,3 & 327,4 & 137,5 & 161,0 & 75,8 & 250,3 & 239,0 & 90,3 & 227,8 & 239,3 & 229,1 & 237,1 & 255,3 & 241,0 & 242,9 & 169,9 & 223,9 \\
\hline $\mathrm{S} / \mathrm{F}$ & 0,1 & 0,6 & 0,5 & 0,0 & 0,5 & 0,5 & 0,5 & 0,6 & 0,5 & 0,5 & 0,5 & 0,5 & 0,6 & 0,5 & 0,5 & 0,5 & 0,5 \\
\hline
\end{tabular}

\begin{tabular}{|c|c|c|c|c|c|c|c|c|c|c|c|c|c|c|c|c|c|}
\hline & \multicolumn{4}{|c|}{ England } & \multicolumn{4}{|c|}{ France } & \multicolumn{4}{|c|}{ Japan } & \multicolumn{5}{|c|}{ South Africa } \\
\hline & 1 & 2 & 3 & 4 & 1 & 2 & 3 & 4 & 1 & 2 & 3 & 4 & 1 & 2 & 3 & 4 & 5 \\
\hline $\mathrm{T} \%$ & $-9,2$ & 4,7 & $-23,8$ & 11,7 & $-14,9$ & 7,0 & $-18,4$ & 6,0 & $-9,5$ & 8,6 & $-24,0$ & 4,9 & 9,1 & $-23,0$ & 5,0 & $-7,9$ & 5,4 \\
\hline G \% & 0,3 & 3,2 & $-2,2$ & $-3,2$ & $-15,9$ & $-2,7$ & 11,0 & $-8,2$ & $-17,9$ & 5,2 & 9,4 & 2,3 & 7,5 & 1,7 & $-31,1$ & 5,4 & $-5,6$ \\
\hline NT & 479,1 & 479,1 & 327,1 & 447,1 & 443,1 & 443,1 & 429,1 & 477,1 & 479,1 & 479,1 & 382,1 & 479,1 & 479,1 & 303,1 & 140,1 & 479,1 & 479,1 \\
\hline $\mathrm{F}$ & 450,4 & 450,8 & 306,3 & 418,6 & 415,6 & 415,4 & 402,9 & 447,4 & 447,5 & 448,9 & 359,3 & 447,0 & 448,8 & 284,4 & 130,8 & 452,5 & 462,9 \\
\hline$S$ & 249,4 & 248,8 & 170,3 & 230,1 & 227,1 & 220,5 & 217,0 & 242,8 & 246,0 & 244,0 & 195,5 & 234,9 & 235,5 & 153,6 & 72,6 & 247,4 & 291,0 \\
\hline $\mathrm{S} / \mathrm{F}$ & 0,6 & 0,6 & 0,6 & 0,5 & 0,5 & 0,5 & 0,5 & 0,5 & 0,5 & 0,5 & 0,5 & 0,5 & 0,5 & 0,5 & 0,6 & 0,5 & 0,6 \\
\hline
\end{tabular}

\begin{tabular}{|c|c|c|c|c|c|c|}
\hline \multicolumn{3}{|c|}{ Argentina } & \multicolumn{3}{|c|}{ South korea } & Australia \\
\hline 1 & 2 & 3 & 1 & 2 & & 3 \\
\hline
\end{tabular}




\begin{tabular}{|c|c|c|c|c|c|c|c|c|c|c|c|c|c|c|c|c|}
\hline T \% & 5,6 & $-34,5$ & 23,4 & 10,1 & $-33,0$ & 10,5 & $-5,2$ & 11,2 & 28,1 & $-34,5$ & 24,4 & $-26,5$ & 6,9 & 7,4 & $-23,0$ & 5,1 \\
\hline G \% & $-5,6$ & 29,0 & 13,0 & 16,4 & 25,4 & 8,0 & 0,1 & 18,5 & 14,4 & $-11,2$ & 92,2 & $-11,0$ & 13,4 & 12,1 & 16,0 & $-6,7$ \\
\hline NT & 479,1 & 259,1 & 479,1 & 479,1 & 235,1 & 479,1 & 479,1 & 479,1 & 479,1 & 479,1 & 153,1 & 187,1 & 479,1 & 479,1 & 304,1 & 470,1 \\
\hline F & 445,9 & 244,0 & 450,0 & 446,9 & 221,4 & 449,9 & 451,3 & 444,4 & 437,3 & 438,1 & 142,0 & 176,4 & 445,0 & 447,5 & 284,0 & 439,4 \\
\hline S & 239,4 & 133,3 & 246,3 & 229,6 & 118,3 & 245,0 & 253,4 & 224,6 & 216,5 & 172,9 & 72,6 & 101,5 & 296,1 & 236,3 & 155,5 & 240,4 \\
\hline S/F & 0,5 & 0,5 & 0,5 & 0,5 & 0,5 & 0,5 & 0,6 & 0,5 & 0,4 & 0,4 & 0,5 & 0,6 & 0,2 & 0,5 & 0,5 & 0,5 \\
\hline
\end{tabular}

\begin{tabular}{|c|c|c|c|c|c|c|c|c|c|c|c|c|c|c|c|c|}
\hline & \multicolumn{6}{|c|}{ Egypt } & \multicolumn{3}{|c|}{ Brézil } & \multicolumn{4}{|c|}{ India } & \multicolumn{3}{|c|}{ Mexico } \\
\hline & 1 & 2 & 3 & 4 & 5 & 6 & 1 & 2 & 3 & 1 & 2 & 3 & 4 & 1 & 2 & 3 \\
\hline T\% & -13.9 & 31.5 & -56.4 & -26.0 & -61.0 & 18.0 & 12.6 & -74.6 & 11.0 & 15.7 & -34.3 & 17.4 & -0.3 & 15.7 & -16.7 & 15.2 \\
\hline G \% & -15.0 & 30.5 & 3.3 & 30.5 & 42.3 & 9.4 & 9.4 & 12.7 & 4.6 & 9.9 & 42.6 & 10.7 & 117.6 & 12.6 & -1.8 & 1.5 \\
\hline NT & 479.1 & 479.1 & 62.1 & 62.1 & 164.1 & 231.1 & 479.1 & 92.1 & 479.1 & 479.1 & 247.1 & 427.1 & 42.1 & 479.1 & 384.1 & 446.1 \\
\hline $\mathrm{F}$ & 446.3 & 442.5 & 59.0 & 80.0 & 155.1 & 216.0 & 447.4 & 86.3 & 449.4 & 444.9 & 230.6 & 401.4 & 39.0 & 479.1 & 360.8 & 420.6 \\
\hline$S$ & 237.4 & 241.3 & 31.8 & 224.5 & 86.0 & 120.4 & 234.9 & 45.8 & 242.1 & 228.8 & 126.9 & 219.9 & 20.8 & 235.8 & 193.6 & 226.6 \\
\hline $\mathrm{S} / \mathrm{F}$ & 0.5 & 0.5 & 0.5 & 2.9 & 0.6 & 0.6 & 0.5 & 0.5 & 0.5 & 0.5 & 0.5 & 0.5 & 0.5 & 0.5 & 0.5 & 0.5 \\
\hline
\end{tabular}

\begin{tabular}{|c|c|c|c|c|c|c|c|c|c|c|c|c|c|c|c|c|c|}
\hline & \multicolumn{6}{|c|}{ Turkey } & \multicolumn{5}{|c|}{ China } & \multicolumn{3}{|c|}{ Indonesia } & \multicolumn{3}{|c|}{ Russia } \\
\hline & 1 & 2 & 3 & 4 & 5 & 6 & 1 & 2 & 3 & 4 & 5 & 1 & 2 & 3 & 1 & 2 & 3 \\
\hline $\mathrm{T} \%$ & $-46,5$ & 14,6 & $-47,9$ & 31,8 & $-38,3$ & 18,7 & 9,4 & $-6,3$ & 33,4 & $-50,9$ & 6,6 & 16,5 & $-39,6$ & 20,3 & 9,1 & $-117,2$ & 17,2 \\
\hline $\mathrm{G} \%$ & $-18,6$ & 14,4 & 63,4 & 23,4 & 33,9 & 5,4 & 4,6 & 7,4 & 31,3 & 9,1 & 3,8 & $-3,1$ & 30,0 & 4,3 & 4,4 & 62,6 & 3,8 \\
\hline NT & 398,1 & 479,1 & 78,1 & 312,1 & 232,1 & 479,1 & 170,1 & 479,1 & 479,1 & 219,1 & 479,1 & 479,1 & 194,1 & 479,1 & 479,1 & 90,1 & 479,1 \\
\hline $\mathrm{F}$ & 371,9 & 479,1 & 73,1 & 291,4 & 217,3 & 479,1 & 159,9 & 479,1 & 479,1 & 205,8 & 479,1 & 479,1 & 183,4 & 479,1 & 479,1 & 84,4 & 479,1 \\
\hline S & 205,8 & 239,3 & 39,1 & 156,5 & 114,8 & 250,6 & 84,6 & 245,4 & 227,3 & 111,4 & 249,5 & 235,1 & 98,4 & 249,9 & 250,1 & 43,8 & 249,1 \\
\hline $\mathrm{S} / \mathrm{F}$ & 0,6 & 0,5 & 0,5 & 0,5 & 0,5 & 0,5 & 0,5 & 0,5 & 0,5 & 0,5 & 0,5 & 0,5 & 0,5 & 0,5 & 0,5 & 0,5 & 0,6 \\
\hline
\end{tabular}

$\mathrm{T} \%:$ Trend in $\%, \quad \mathrm{G} \%:$ Average gain in $\%, \mathrm{NT}:$ Average number of transactions, $\mathrm{F}:$ Average failure,

$\mathrm{S}:$ Average success, S/F : Average success / Failure

Appendix 3. Excess Returns

\begin{tabular}{|c|c|c|c|c|c|c|c|c|c|c|c|c|c|c|c|c|c|c|c|}
\hline \multirow{3}{*}{\multicolumn{2}{|c|}{$\begin{array}{c}\text { Developed } \\
\text { countries }\end{array}$}} & \multicolumn{9}{|c|}{ Per period } & \multicolumn{9}{|c|}{ Whole period } \\
\hline & & \multirow{2}{*}{ Hurst } & \multicolumn{8}{|c|}{ Excess returns } & \multirow{2}{*}{ Hurst } & \multicolumn{8}{|c|}{ Excess returns } \\
\hline & & & BB & $\begin{array}{c}\text { MAC } \\
\text { D }\end{array}$ & M & MA & ROC & RSI & TRIX & $\mathrm{ZZ}$ & & $\mathrm{BB}$ & $\begin{array}{c}\text { MAC } \\
\text { D }\end{array}$ & M & MA & ROC & RSI & TRIX & $\mathrm{ZZ}$ \\
\hline \multirow{4}{*}{$\begin{array}{l}\stackrel{\Xi}{\Xi} \\
\stackrel{\Xi}{\Xi}\end{array}$} & 1 & 0,56 & $-0,02$ & 0,11 & 0,86 & 0,15 & 0,28 & $-0,04$ & 0,30 & $-0,07$ & \multirow{4}{*}{0,56} & \multirow{4}{*}{0,01} & \multirow{4}{*}{$-0,08$} & \multirow{4}{*}{0,22} & \multirow{4}{*}{0,05} & \multirow{4}{*}{0,44} & \multirow{4}{*}{$-0,05$} & \multirow{4}{*}{0,07} & \multirow{4}{*}{$-0,02$} \\
\hline & 2 & 0,52 & $-0,02$ & $-0,09$ & $-0,11$ & $-0,01$ & $-0,02$ & $-0,19$ & $-0,04$ & $-0,04$ & & & & & & & & & \\
\hline & 3 & 0,52 & 0,06 & $-0,10$ & 0,22 & 0,07 & 1,60 & 0,03 & 0,16 & 0,16 & & & & & & & & & \\
\hline & 4 & 0,46 & 0,02 & $-0,24$ & $-0,12$ & 0,00 & $-0,11$ & 0,01 & $-0,13$ & $-0,13$ & & & & & & & & & \\
\hline
\end{tabular}




\begin{tabular}{|c|c|c|c|c|c|c|c|c|c|c|c|c|c|c|c|c|c|c|c|}
\hline \multirow{5}{*}{ 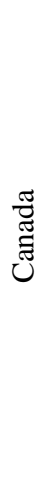 } & 1 & 0,55 & 0,02 & 0,04 & $-0,16$ & $-0,01$ & 0,03 & $-0,56$ & 0,01 & 0,01 & \multirow{5}{*}{0,56} & \multirow{5}{*}{0,03} & \multirow{5}{*}{0,37} & \multirow{5}{*}{0,04} & \multirow{5}{*}{0,01} & \multirow{5}{*}{0,20} & \multirow{5}{*}{0,01} & \multirow{5}{*}{0,02} & \multirow{5}{*}{0,02} \\
\hline & 2 & 0,52 & 0,06 & 0,65 & 0,15 & 0,07 & 0,10 & 0,46 & 0,04 & 0,04 & & & & & & & & & \\
\hline & 3 & 0,51 & 0,00 & $-0,02$ & $-0,03$ & 0,00 & 0,14 & 0,29 & 0,00 & 0,00 & & & & & & & & & \\
\hline & 4 & 0,52 & 0,07 & 1,46 & 0,34 & 0,02 & 1,16 & 0,22 & 0,04 & 0,04 & & & & & & & & & \\
\hline & 5 & 0,56 & 0,01 & $-0,28$ & $-0,12$ & $-0,02$ & $-0,44$ & $-0,36$ & 0,01 & 0,01 & & & & & & & & & \\
\hline \multirow{4}{*}{ 吾 } & 1 & 0,51 & 0,00 & 0,16 & $-0,06$ & 0,00 & 0,38 & $-0,03$ & 0,00 & 0,00 & \multirow{4}{*}{0,56} & \multirow{4}{*}{0,02} & \multirow{4}{*}{0,20} & \multirow{4}{*}{0,03} & \multirow{4}{*}{0,01} & \multirow{4}{*}{0,29} & \multirow{4}{*}{0,45} & \multirow{4}{*}{0,02} & \multirow{4}{*}{0,02} \\
\hline & 2 & 0,45 & 0,03 & 0,63 & 0,19 & 0,04 & 0,74 & 1,22 & 0,02 & 0,02 & & & & & & & & & \\
\hline & 3 & 0,77 & 0,03 & $-0,31$ & $-0,20$ & 0,00 & $-0,13$ & $-0,60$ & 0,02 & 0,02 & & & & & & & & & \\
\hline & 4 & 0,52 & 0,02 & 0,34 & 0,18 & $-0,01$ & 0,16 & 1,20 & 0,02 & 0,02 & & & & & & & & & \\
\hline \multirow{4}{*}{$\underset{\mathscr{\Omega}}{\mathbb{\Omega}}$} & 1 & 0,45 & 0,01 & $-0,58$ & 0,08 & 0,02 & 0,29 & $-0,33$ & 0,00 & 0,00 & \multirow{4}{*}{0,54} & \multirow{4}{*}{0,01} & \multirow{4}{*}{$-0,06$} & \multirow{4}{*}{0,03} & \multirow{4}{*}{0,01} & \multirow{4}{*}{0,24} & \multirow{4}{*}{$-0,04$} & \multirow{4}{*}{0,01} & \\
\hline & 2 & 0,40 & 0,00 & $-0,02$ & $-0,03$ & $-0,01$ & 0,06 & $-0,02$ & 0,00 & 0,00 & & & & & & & & & \\
\hline & 3 & 0,42 & 0,04 & 0,64 & 0,21 & 0,05 & 1,22 & 0,48 & 0,03 & 0,03 & & & & & & & & & \\
\hline & 4 & 0,57 & 0,01 & $-0,27$ & $-0,14$ & $-0,02$ & $-0,60$ & $-0,31$ & 0,01 & 0,01 & & & & & & & & & \\
\hline & 1 & 0,42 & $-0,01$ & 0,18 & 0,07 & 0,00 & 0,41 & 0,08 & $-0,03$ & $-0,03$ & & & & & & & & & \\
\hline$\vec{\Xi}$ & 2 & 0,59 & 0,00 & 0,01 & $-0,05$ & $-0,01$ & $-0,10$ & 0,09 & 0,00 & 0,00 & & & & & & & & & \\
\hline $\bar{I}$ & 3 & 0,54 & 0,02 & 0,32 & 0,20 & 0,03 & 1,25 & $-0,11$ & $-0,01$ & $-0,01$ & & & & & & & & & \\
\hline & 4 & 0,60 & 0,00 & $-0,05$ & $-0,11$ & $-0,02$ & $-0,57$ & $-0,34$ & $-0,02$ & $-0,02$ & & & & & & & & & \\
\hline & 1 & 0,44 & 0,03 & $-0,54$ & 0,14 & 0,02 & 0,39 & $-0,36$ & 0,03 & 0,03 & & & & & & & & & \\
\hline & 2 & 0,47 & 0,01 & $-0,18$ & $-0,08$ & 0,00 & $-0,21$ & $-0,12$ & 0,01 & 0,01 & & & & & & & & & \\
\hline L & 3 & 0,44 & 0,04 & 0,46 & 0,14 & 0,02 & 0,70 & 0,98 & 0,02 & 0,02 & & & & & & & & & \\
\hline & 4 & 0,45 & $-0,01$ & $-0,45$ & $-0,07$ & 0,01 & $-0,11$ & $-0,41$ & $-0,01$ & $-0,01$ & & & & & & & & & \\
\hline
\end{tabular}




\begin{tabular}{|c|c|c|c|c|c|c|c|c|c|c|c|c|c|c|c|c|c|c|c|}
\hline & 1 & 0,51 & 0,01 & $-0,53$ & 0,10 & 0,00 & $-0,13$ & $-0,35$ & 0,00 & 0,00 & \multirow{4}{*}{0,53} & \multirow{4}{*}{0,02} & \multirow{4}{*}{$-0,06$} & \multirow{4}{*}{0,04} & \multirow{4}{*}{0,01} & \multirow{4}{*}{0,31} & \multirow{4}{*}{$-0,01$} & \multirow{4}{*}{0,01} & \multirow{4}{*}{0,01} \\
\hline \multirow{3}{*}{$\begin{array}{l}\text { 志 } \\
\text { 胥 }\end{array}$} & 2 & 0,51 & 0,01 & $-0,17$ & $-0,08$ & 0,01 & 0,36 & $-0,31$ & 0,01 & 0,01 & & & & & & & & & \\
\hline & 3 & 0,50 & 0,05 & 0,58 & 0,20 & 0,03 & 0,90 & 0,79 & 0,03 & 0,03 & & & & & & & & & \\
\hline & 4 & 0,57 & 0,01 & $-0,10$ & $-0,05$ & 0,01 & 0,11 & $-0,15$ & 0,01 & 0,01 & & & & & & & & & \\
\hline \multicolumn{3}{|c|}{ Profitability } & 20 & 13 & 14 & 19 & 19 & 12 & 21 & 20 & & 7 & 3 & 7 & 6 & 7 & 3 & 6 & 5 \\
\hline
\end{tabular}

\begin{tabular}{|c|c|c|c|c|c|c|c|c|c|c|c|c|c|c|c|c|c|c|c|}
\hline \multirow{3}{*}{\multicolumn{2}{|c|}{$\begin{array}{l}\text { Emerging } \\
\text { countries }\end{array}$}} & \multicolumn{9}{|c|}{ Per period } & \multicolumn{9}{|c|}{ Whole period } \\
\hline & & \multirow{2}{*}{ Hurst } & \multicolumn{8}{|c|}{ Excess returns } & \multirow{2}{*}{ Hurst } & \multicolumn{8}{|c|}{ Excess returns } \\
\hline & & & $\mathrm{BB}$ & MACD & M & MA & ROC & RSI & TRIX & $\mathrm{ZZ}$ & & BB & MACD & M & MA & ROC & RSI & TRIX & $\mathrm{ZZ}$ \\
\hline \multirow{5}{*}{ 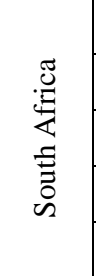 } & 1 & 0,37 & 0,01 & 0,09 & $-0,09$ & $-0,01$ & $-0,04 \mid$ & $-0,04$ & 0,03 & 0,03 & \multirow{5}{*}{0,51} & \multirow{5}{*}{0,03} & \multirow{5}{*}{$-0,30$} & \multirow{5}{*}{0,02} & \multirow{5}{*}{0,02} & \multirow{5}{*}{0,06} & \multirow{5}{*}{$-0,04$} & \multirow{5}{*}{0,03} & \multirow{5}{*}{0,03} \\
\hline & 2 & 0,53 & $-0,01$ & 0,03 & 0,26 & $-0,04$ & 0,83 & 0,61 & 0,03 & 0,03 & & & & & & & & & \\
\hline & 3 & 0,52 & 0,04 & $-1,71$ & $-0,03$ & 0,09 & $-0,59$ & $-0,76$ & 0,01 & 0,01 & & & & & & & & & \\
\hline & 4 & 0,53 & 0,08 & 0,29 & 0,03 & 0,08 & 0,34 & 0,28 & 0,04 & 0,04 & & & & & & & & & \\
\hline & 5 & 0,60 & 0,02 & $-0,20$ & $-0,06$ & 0,01 & $-0,26$ & $-0,27$ & 0,03 & 0,03 & & & & & & & & & \\
\hline.$\tilde{g}$ & 1 & 0,54 & 0,02 & $-0,20$ & $-0,06$ & 0,00 & $-0,26$ & $-0,28$ & 0,03 & 0,03 & \multirow{3}{*}{0,57} & \multirow{3}{*}{0,02} & \multirow{3}{*}{0,29} & \multirow{3}{*}{0,01} & \multirow{3}{*}{0,04} & \multirow{3}{*}{0,14} & & & \\
\hline 莺 & 2 & 0,54 & 0,05 & 0,98 & 0,33 & 0,10 & 1,06 & 2,25 & 0,03 & 0,03 & & & & & & & 0,61 & 0,02 & 0,02 \\
\hline & 3 & 0,52 & 0,00 & 0,09 & $-0,24$ & 0,01 & \begin{tabular}{|l|}
$-0,37$ \\
\end{tabular} & $-0,13$ & $-0,01$ & $-0,01$ & & & & & & & & & \\
\hline & 1 & 0,37 & 0,00 & 0,48 & $-0,07$ & $-0,01$ & 0,13 & $-0,04$ & 0,00 & 0,00 & & & & & & & & & \\
\hline 志 & 2 & 0,53 & 0,14 & 1,06 & 0,20 & 0,17 & 2,38 & 0,71 & 0,02 & 0,02 & 0,53 & 0,05 & 0,56 & 0,01 & 0,06 & 0,73 & 0,23 & 0,01 & 0,01 \\
\hline & 3 & 0,62 & 0,01 & 0,15 & $-0,09$ & 0,02 & $-0,32$ & 0,02 & 0,01 & 0,01 & & & & & & & & & \\
\hline$\stackrel{\varrho}{=} \sigma$ & 1 & 0,54 & 0,00 & 0,00 & 0,06 & 0,00 & $-0,25 \mid$ & 0,47 & $-0,01$ & $-0,01$ & 060 & 0,0 & 010 & 003 & 001 & 016 & 017 & 0,01 & O \\
\hline$E$ & 2 & 0,62 & \begin{tabular}{|l|}
0,00 \\
\end{tabular} & 0,39 & $-0,11$ & 0,01 & \begin{tabular}{|l|}
0,57 \\
\end{tabular} & $-0,12$ & 0,00 & 0,00 & 0,00 & 0,00 & 0,19 & $-0,03$ & 0,01 & 0,10 & 0,17 & $-0,01$ & $\left.\right|^{-0,01}$ \\
\hline & 1 & 0,53 & 0,01 & 0,04 & $-0,29$ & 0,00 & $-0,37$ & $-0,18$ & 0,02 & 0,02 & & & & & & & & & \\
\hline ) & 2 & 0,53 & 0,06 & $-0,18$ & 0,35 & 0,08 & 0,25 & 1,05 & 0,04 & 0,04 & & & & & & & & & \\
\hline $\begin{array}{l}\tilde{\Xi} \\
i \bar{z}\end{array}$ & 3 & 0,55 & $-0,06$ & 1,61 & $-0,14$ & \begin{tabular}{|l}
$-0,07$ \\
\end{tabular} & \begin{tabular}{|l|}
1,31 \\
\end{tabular} & 2,70 & 0,01 & 0,01 & 0,58 & 0,02 & 0,37 & 0,01 & 0,02 & 0,44 & 0,78 & 0,02 & 0,02 \\
\hline 胥 & 4 & 0,51 & 0,06 & 0,08 & 0,20 & 0,12 & 0,84 & 0,09 & 0,02 & 0,02 & & & & & & & & & \\
\hline & 5 & 0,70 & 0,00 & 0,30 & $-0,07$ & 0,00 & 0,18 & 0,25 & 0,00 & 0,00 & & & & & & & & & \\
\hline 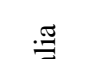 & 1 & 0,46 & 0,01 & 0,10 & $-0,07$ & $-0,01$ & 0,29 & 0,07 & 0,01 & 0,01 & & & & & & & & & \\
\hline$\frac{\pi}{5}$ & 2 & 0,53 & 0,04 & 0,23 & 0,19 & 0,03 & \begin{tabular}{|l|}
2,39 \\
\end{tabular} & 0,09 & 0,02 & 0,02 & 0,54 & 0,02 & 0,04 & 0,02 & 0,01 & 0,79 & $-0,04$ & 0,01 & 0,01 \\
\hline$\varangle$ & 3 & 0,52 & 0,01 & $-0,21$ & $-0,06$ & 0,01 & $-0,31$ & $-0,29$ & \begin{tabular}{l|}
0,01 \\
\end{tabular} & 0,01 & & & & & & & & & \\
\hline & 1 & 0,53 & 0,07 & $-0,45$ & 0,15 & 0,08 & $-0,21$ & \begin{tabular}{|l|}
0,00 \\
\end{tabular} & 0,07 & 0,07 & & & & & & & & & \\
\hline & 2 & 0,53 & 0,07 & 0,30 & $-0,29$ & 0,05 & 0,08 & $-0,13$ & 0,08 & 0,08 & & & & & & & & & \\
\hline$\vec{n}$ & 3 & 0,58 & 0,25 & 1,18 & 0,29 & 0,36 & 2,29 & 0,47 & 0,04 & 0,04 & 0.57 & 0.19 & 0.63 & 0.11 & 0.20 & 0.98 & 0.46 & 0.15 & 015 \\
\hline 吕 & 4 & 0,39 & 0,64 & 0,88 & 0,29 & 0,63 & 0,65 & 0,44 & 0,65 & 0,65 & , & 0,19 & 0,03 & 0,11 & 0,20 & 0,98 & 0,40 & 0,13 & 0,13 \\
\hline & 5 & 0,46 & 0,10 & 1,82 & 0,44 & 0,08 & 3,52 & 2,01 & 0,04 & 0,04 & & & & & & & & & \\
\hline & 6 & 0,53 & 0,04 & 0,05 & $-0,19$ & 0,03 & $-0,41$ & $-0,02$ & 0,05 & 0,05 & & & & & & & & & \\
\hline Prof & fitabi & ility & 23 & 20 & 12 & 21 & 16 & 16 & 24 & 24 & & 6 & 6 & 6 & 7 & 7 & 5 & 6 & 6 \\
\hline
\end{tabular}




\begin{tabular}{|c|c|c|c|c|c|c|c|c|c|c|c|c|c|c|c|c|c|c|c|}
\hline \multirow{3}{*}{ 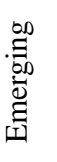 } & \multirow{3}{*}{$\begin{array}{l}\tilde{\Delta} \\
\dot{0} \\
\vdots \\
\vdots\end{array}$} & \multicolumn{9}{|c|}{ Per period } & \multicolumn{9}{|c|}{ Whole period } \\
\hline & & \multirow{2}{*}{ Hurst } & \multicolumn{8}{|c|}{ Excess returns } & \multirow{2}{*}{ Hurst } & \multicolumn{8}{|c|}{ Excess returns } \\
\hline & & & BB & MACD & M & MA & ROC & RSI & TRIX & $\mathrm{ZZ}$ & & $\mathrm{BB}$ & MACD & M & MA & ROC & RSI & TRIX & $\mathrm{ZZ}$ \\
\hline \multirow{3}{*}{ 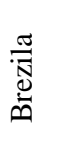 } & 1 & 0,51 & $-0,02$ & 0,00 & $-0,09$ & 0,00 & $-0,17$ & $-0,15$ & $-0,01$ & $-0,01$ & \multirow{3}{*}{0,53} & \multirow{3}{*}{0,04} & \multirow{3}{*}{0,63} & \multirow{3}{*}{0,15} & \multirow{3}{*}{0,09} & \multirow{3}{*}{0,43} & \multirow{3}{*}{0,54} & \multirow{3}{*}{0,02} & \multirow{3}{*}{0,02} \\
\hline & 2 & 0,39 & 0,12 & 1,63 & 0,63 & 0,25 & 1,78 & 2,04 & 0,07 & 0,07 & & & & & & & & & \\
\hline & 3 & 0,52 & 0,00 & 0,26 & $-0,11$ & 0,02 & $-0,31$ & $-0,27$ & 0,01 & 0,01 & & & & & & & & & \\
\hline \multirow{4}{*}{$\stackrel{\stackrel{\Xi}{\Xi}}{\Xi}$} & 1 & 0,52 & 0,02 & 0,07 & $-0,16$ & $-0,01$ & $-0,18$ & $-0,06$ & 0,03 & 0,03 & \multirow{4}{*}{0,55} & \multirow{4}{*}{0,00} & \multirow{4}{*}{0,45} & \multirow{4}{*}{0,02} & \multirow{4}{*}{0,01} & & & & \\
\hline & 2 & 0,54 & 0,04 & 1,18 & 0,31 & 0,06 & 3,29 & 0,97 & 0,04 & 0,04 & & & & & & & & & \\
\hline & 3 & 0,53 & $-0,01$ & 0,34 & $-0,22$ & 0,00 & $-0,41$ & $-0,12$ & 0,02 & 0,02 & & & & & & 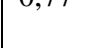 & 2,22 & 0,02 &, 02 \\
\hline & 4 & 0,52 & $-0,04$ & 0,20 & 0,13 & $-0,02$ & 0,40 & 8,09 & 0,01 & 0,01 & & & & & & & & & \\
\hline & 1 & 0,51 & 0,01 & 0,01 & $-0,15$ & 0,01 & $-0,06$ & 0,11 & 0,01 & 0,01 & & & & & & & & & \\
\hline ex & 2 & 0,52 & 0,05 & 0,05 & 0,16 & 0,06 & 0,30 & 0,39 & 0,02 & 0,02 & 0,55 & 0,02 & $-0,05$ & $-0,05$ & 0,02 & 0,01 & 0,02 & 0,01 & 0,01 \\
\hline & 3 & 0,52 & 0,02 & $-0,20$ & $-0,15$ & $-0,01$ & $-0,22$ & $-0,45$ & 0,01 & 0,01 & & & & & & & & & \\
\hline & 1 & 0,51 & 0,11 & 0,39 & 0,39 & 0,12 & 0,42 & 0,35 & 0,11 & 0,11 & & & & & & & & & \\
\hline & 2 & 0,53 & 0,02 & 0,15 & $-0,15$ & 0,01 & $-0,19$ & 0,24 & 0,03 & 0,03 & & & & & & & & & \\
\hline 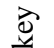 & 3 & 0,52 & 0,11 & 2,33 & 0,42 & 0,23 & 1,81 & 3,80 & 0,04 & 0,04 & 052 & $0 \cap 6$ & 066 & 007 & 0 & 076 & 002 & $0 \cap$ & 004 \\
\hline$\Xi$ & 4 & 0,52 & 0,04 & 0,26 & $-0,32$ & 0,02 & $-0,27$ & $-0,16$ & 0,05 & 0,05 & 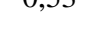 & 0,00 & 0,00 & 0,01 & 0,10 & 0,1 & J, J & $0,0+$ & 0,04 \\
\hline & 5 & 0,52 & 0,10 & 1,00 & 0,28 & 0,17 & 2,94 & 1,12 & 0,03 & 0,03 & & & & & & & & & \\
\hline & 6 & 0,53 & 0,00 & $-0,17$ & $-0,19$ & 0,03 & $-0,14$ & $-0,39$ & $-0,02$ & $-0,02$ & & & & & & & & & \\
\hline & 1 & 0,34 & 0,07 & 0,53 & $-0,08$ & 0,08 & $-0,32$ & $-0,37$ & 0,01 & 0,01 & & & & & & & & & \\
\hline & 2 & 0,52 & 0,01 & 0,20 & 0,06 & 0,02 & 0,08 & 0,62 & 0,00 & 0,00 & & & & & & & & & \\
\hline 踝 & 3 & 0,51 & 0,00 & 0,34 & $-0,32$ & 0,00 & 0,24 & $-0,18$ & 0,01 & 0,01 & 0,57 & 0,03 & 0,36 & 0,00 & 0,05 & 0,52 & 0,11 & 0,01 & 0,01 \\
\hline & 4 & 0,49 & \begin{tabular}{|l}
0,09 \\
\end{tabular} & 0,50 & 0,41 & 0,12 & 2,85 & 0,73 & 0,04 & 0,04 & & & & & & & & & \\
\hline & 5 & 0,53 & 0,01 & 0,20 & $-0,05$ & 0,01 & $-0,26$ & $-0,24$ & 0,00 & 0,00 & & & & & & & & & \\
\hline.$\frac{\pi}{0}$ & 1 & 0,54 & 0,01 & $-0,12$ & $-0,18$ & 0,01 & $-0,61$ & $-0,50$ & 0,02 & 0,02 & & & & & & & & & \\
\hline$\tilde{0}$ & 2 & 0,52 & 0,09 & 2,30 & 0,28 & 0,17 & 1,34 & 1,17 & 0,03 & 0,03 & 0,58 & 0,03 & 0,91 & $-0,04$ & 0,06 & $-0,06$ & 0,06 & 0,02 & 0,02 \\
\hline$\Xi$ & 3 & 0,52 & 0,00 & 0,56 & $-0,22$ & 0,02 & $-0,91$ & $-0,49$ & 0,00 & 0,00 & & & & & & & & & \\
\hline & 1 & 0,55 & $-0,04$ & $-0,17$ & $-0,03$ & $-0,04$ & $-0,07$ & $-0,07$ & $-0,05$ & $-0,05$ & & & & & & & & & \\
\hline$\underline{0}$ & 2 & 0,29 & 0,28 & 3,70 & 0,62 & 0,39 & 4,98 & 3,70 & 0,13 & 0,13 & 0,54 & 0,09 & 1,14 & 0,15 & 0,13 & 1,44 & 1,11 & 0,04 & 0,04 \\
\hline & 3 & 0,55 & 0,03 & $-0,12$ & $-0,15$ & 0,03 & $-0,58$ & $-0,30$ & 0,03 & 0,03 & & & & & & & & & \\
\hline Pro & fital & bility & 22 & 21 & 11 & 21 & 12 & 13 & 23 & 23 & & 7 & 6 & 5 & 7 & 6 & 7 & 7 & 7 \\
\hline
\end{tabular}

BB : Bollinger Bands, M : Momentum, MA : Moving Average, ROC : Price ROC, RSI : Relative Strength Index,

$\mathrm{ZZ}:$ Zig Zag

\section{Copyright Disclaimer}

Copyright reserved by the author(s).

This article is an open-access article distributed under the terms and conditions of the Creative Commons Attribution license (http://creativecommons.org/licenses/by/3.0/). 